\title{
External Imbalances in the European Union and International Fragmentation of Production: Is There a Link?*
}

\author{
Isabella Cingolani ${ }^{\dagger} \quad$ Giulia Felice ${ }^{\ddagger} \quad$ Lucia Tajoli ${ }^{\S}$
}

March 2015

\begin{abstract}
In this paper we assess whether the expansion of international fragmentation of production (IFP) and the creation of production linkages among European countries contribute to the trade imbalances registered within the European Union (EU) area in the past decade. Exporting intermediate and semi-finished goods and re-importing finished and assembled goods can give rise to a trade deficit, but such international reorganization of production allows countries to improve their efficiency and competitiveness (both in terms of cost reduction and higher quality of goods) and to gain access to new export markets. The net effect on the trade balances is therefore ambiguous.
\end{abstract}

*The authors are grateful for the useful comments received from the participants to seminars and conferences in which previous versions of the paper were presented, among which are the seminar series at the U.S. International Trade Commission (2015), the Univ. Complutense of Madrid (2015), the Univ. Carlos III of Madrid (2014), the Univ. of Barcelona (2014), XXVI Villa Mondragone International Economic Seminar (Rome, 2014), and the conferences ERSA (Saint Petersburg, 2014), IAES (Madrid, 2014), ETSG (Birmingham, 2013), ITSG (Fiesole, EUI, 2013). The authors wish to thank the Politecnico of Milan for its financial support under the Farb funding scheme (2011). Giulia Felice gratefully acknowledges the financial assistance from the Marie Curie IEF project (N. PIEF-GA-2012-329153) funded by the European Commission under the Seventh Framework Programme. The usual disclaimer applies.

†Dipartimento di Ingegneria Gestionale, Politecnico di Milano - piazza Leonardo da Vinci 32, Milano 20133, Italy. +390223992752. isabella.cingolani@polimi.it

$\ddagger$ Department of Economics, Universidad Carlos III de Madrid and Centro Studi Luca d'Agliano. gfelice@eco.uc3m.es

§Dipartimento di Ingegneria Gestionale, Politecnico di Milano - piazza Leonardo da Vinci 32, Milano 20133, Italy. +390223992752. lucia.tajoli@polimi.it. 
We test empirically the sign of this effect, using the recently released WIOD database on international production linkages. We find that the current account in EU countries worsens the higher the offshoring to low-income partners. By contrast, the current account improves by offshoring to high-income partners. This asymmetry suggests that when countries offshore to high-income partners the gains in competitiveness overcome the potentially negative effect of importing intermediate inputs.

KEYWORDS: trade balances, offshoring, European Union.

JEL Classification: F14, F15, F62. 


\section{Introduction}

The rapid increase of international trade in intermediate and semi-finished goods in the past twenty years has been studied extensively in the international trade literature in order to understand how the shift from trade in final goods to this "vertical trade" affected the trade patterns and specialization of countries (Deardorff, 2001; Hummels et al., 2001; Yi, 2003). Intermediate goods are today estimated to account for over half of the total goods' trade and over two thirds of the services' trade (Miroudot and Ragousiss, 2009). The growing relevance of trade in intermediate goods is directly related to the expansion of international fragmentation of production (IFP), or the development of international production chains stretching across different countries, where the various production phases and the creation of value added for a given final good is taking place in different locations. This phenomenon, initially studied especially for the U.S., has become increasingly relevant also for the European Union (EU), affecting both extra-EU and intra-EU trade relations (Egger and Egger, 2005; Baldone et. al, 2007). In particular, both the deep integration process that accompanied the introduction of the single European currency and the enlargement of the EU to the Central and Eastern European Countries (CEECs) fostered the integration of production processes across the EU, giving rise to extensive intra-European production chains.

International fragmentation of production and the high share of intermediate goods on overall trade flows led scholars to partially revise the traditional measures of trade flows across countries and the related indexes of comparative advantage (Deardorff, 2005; Baldone et. al, 2007; Stehrer, 2012; Koopman et al., 2014), while generally less attention has been devoted to the implications of this type of trade for countries' trade balances. ${ }^{1}$ The macroeconomic effects of IFP started to be discussed only recently in the international economics literature, prompted by the widening trade imbalances and sharp trade fluctuations registered before and during the global crisis (Arkolakis and Ramanarayanan, 2009; Escaith et al., 2010; Levchenko et al., 2010; Gopinath and Neiman, 2011; Falzoni and Tajoli, 2015). But the extent and form of participation of a country in the global value chain might affect the amount of its exports and imports in the medium term, well beyond the business cycle effects, thereby affecting its trade balance.

\footnotetext{
${ }^{1}$ As awareness of the growing impact of IFP on trade flows, and thereby on trade balances, grew, some international projects (WIOD, OECD-WTO, GTAP, UNCTAD, IDEJETRO) began to develop specific measures of bilateral trade balances in terms of value added, now available for a subset of countries (see also Unctad, 2013; Elms and Low, 2013).
} 
A recent macroeconomic policy debate has also emerged, in particular focusing on China's persistent external surplus, on the role of imported input in external sector adjustment. Several works show that exchange rate may have a different effect than expected if the share of domestic value added in exports is small, due to the role of a country as a processing hub (Marquez and Schindler, 2007; Thorbecke and Smith, 2010; Cheung et al., 2012). The underlining idea is that different types of trade might respond differently to exchange rate movements. These empirical studies put forward a potentially substantial role for input in external sector adjustment, this way implicitly calling for a deeper understanding of the role of IFP as a potential medium-term determinant of a country's external position.

For over a decade, macroeconomic data showed a large and widening increase in the current account imbalances all over the world, as if some structural global change had occurred. The problem was exacerbated right before the burst of the 2008 crisis when some countries' balances had become a reason for serious concern. The issue might also play a role for the European countries. As the EU countries were increasingly seriously affected by the financial tensions, it became apparent that one of the dimensions of the EU problems was the persistent difference in its members' trade balances. In fact, while the EU as a whole with respect to the rest of the world has a nearly balanced trade, its member states appear quite differentiated in this respect (Guerrieri and Esposito, 2012; Belke and Dreger, 2013; Coudert et. al., 2013).

The aim of this paper is to explore the possible relationship between these trade imbalances of the EU countries and the phenomenon of IFP within Europe.

There is no clear a priori effect of IFP on a country's trade balance. On the one hand, considering a specific country pair in the global value chain, exporting intermediate and semi-finished goods and re-importing finished and assembled goods can give rise to a trade deficit (both in gross terms and in value added terms, but with different magnitudes) for the country in the upstream part of the international production chain, while it can originate a trade surplus for downstream countries. On the other hand, if this international reorganization of production allows countries to improve their competitiveness and to gain access (even indirectly) to new export markets, the effect on trade balances can be positive. This competitiveness channel can develop along different lines. Higher competitiveness through IFP can be reached through cost and, therefore, price reduction (Deardorff, 2001; Baldone et al., 2002); it can arise through technological improvements or factors' productivity enhancement (Grossman and Rossi-Hansberg, 2008; Halpern et al., 2011) and through the quality of intermediate inputs and components from abroad 
incorporated in a country's final product. Several recent contributions have highlighted the link between the quality of inputs and the quality of output and the role of non-price competitiveness in countries' external performance (Verhoogen, 2008; Kugler and Verhoogen, 2012). Last, but not least, a country's involvement and position in the global value chain can also be related to its external position through income effects. International fragmentation of production can affect both the within and the between countries' income distribution depending on a country's position in the global value chain and the tasks offshored (Grossman and Rossi-Hansberg, 2008; Costinot et al., 2013; Timmer et al., 2013, 2014), with ambiguous consequences on the current account. Moreover, it typically affects the income distribution among different sources of income that may have different saving and consumption behaviour, again with ambiguous implications on the current account.

The sign and magnitude of the effects of IFP on a country's medium-term external position are thus open to empirical investigation. We investigate empirically whether a country's involvement in IFP is a potential medium-term determinant of its current account, along with the others structural mediumterm determinants highlighted by the macroeconomic literature (Razin, 1995; Obstfeld and Rogoff, 1998). We compute two indicators of a country's participation in the global value chain, the Feenstra and Hanson (1996) offshoring indicator, and the share of foreign value added in a country's gross export recently proposed by Koopman et al. (2014), by using the World Input Output Database (WIOD). We employ an empirical model of medium-term current account determinants along the lines of Chinn and Prasad (2003) and Lane and Milesi-Ferretti (2012) in order to explore the relationship between participation in the global value chains, proxied by the two indicators, and the current account position for the EU countries. Our results show that the involvement of a country in IFP can indeed affect its trade balances, also through the presence of a pro-competitiveness effect. But the sign of this relationship crucially depends on the type and source of offshoring. In particular, we find that offshoring to low-income/low-product quality (highincome/high-product quality) partners is negatively (positively) related with a country's current account. We also show that this result is especially relevant for the Eastern EU countries, suggesting that both the quality of the domestic demand and the segment of competition (low vs. high quality) in the foreign market matter.

This paper is related to three main streams of literature. It contributes to the literature investigating medium-term determinants of current account imbalances within the EU (see Section 2), by investigating the role of a country's participation in the IFP as a potential determinant of its exter- 
nal position. It contributes to the stream of literature recently emerged on indexes of countries' involvement in the global value chain by looking at its implications on the aggregate external position. The contributions belonging to this already large stream of literature provide new sophisticated indicators, new data and conceptual categories on the IFP, showing several stylized facts on trade specialization patterns highlighting the difference in gross and net terms, factor income shares' dynamics and patterns across countries, and patterns of foreign and domestic value added content in gross export and production (Daudin et al., 2011; Antras et al., 2012; Johnson and Noguera, 2012; Stehrer, 2012; Timmer et al., 2013, 2014; Koopman et al., 2014). Recently, Johnson (2014) underlines the relevance of the value - added view of trade with respect to the adjustment of trade imbalances, by changing the size of the required real exchange rate variation; along the same lines, Bems (2014) shows that traditional multi-sector macro models without production inputs generate different predictions regarding the relative price response to external rebalancing when calibrated, by using gross - flows trade data instead of value added trade data. Last but not least our paper contributes to the fast-growing literature on non-price competitiveness and the role of quality in international trade (among others, Falvey and Kierzkowski, 1987; Flam and Helpman, 1987; Hallak, 2006; Verhoogen, 2008; Crozet et al., 2012; Feenstra and Romalis, 2012), explicitly considering the role of input quality in assessing the effects of a country's participation in IFP. To the best of our knowledge, our contribution represents an original attempt to investigate the relationship between different indicators of IFP and the current account, in particular by focusing on EU countries and differentiating by partners in the offshoring relationship.

The structure of the paper is as follows: the next section illustrates some descriptive evidence of trade balances and offshoring in the EU; Section 3 reports our empirical estimation of the relationship between offshoring and current account balances; Section 4 concludes.

\section{Trade balances and offshoring in the EU}

As mentioned, in the years before the global financial crisis, the EU as a whole had remained relatively close to external balance, while the current account (CA) balances and the competitive positions of individual member countries had widely diverged. After the introduction of the euro and before the crisis (2002 - 2007), Figures 1 and 2 show a clear divide in the euro area between surplus-northern countries and deficit-southern/eastern countries. With the slowdown of the EU economies following the international financial 
crisis, some signs of rebalancing are appearing (see Fig. 3).

This pattern of imbalances within the European area and its persistence have been generally explained by the "traditional" macroeconomic factors (Blanchard and Giavazzi, 2002; Guillemette and Turner, 2013), i.e. by those countries' differences in their macroeconomic fundamentals, in line with the intertemporal approach to current account determination (Razin,1995; Obstfeld and Rogoff,1998). It is nevertheless worth noting that these explanations are only part of the story, and also some other components might play a role. As discussed by Chen et al. (2012), the two main explanations refer to the rising financial integration among euro area countries that increased financial flows toward the area's debtor countries, and to wage and price rigidities of this same group of countries. Both effects brought about a significant real effective exchange rate appreciation in many southern countries (even if to a different extent). Therefore, the external divergence is directly related to a steady widening of differences in the competitive positions of the two groups of countries (see also Belke and Dreger, 2013; Coudert et. al., 2013). However, Chen et al. (2012) show that trade and financial flows between the euro area countries and the rest of the world also played an important role in explaining the different external imbalances, as the impact of trade developments with countries outside the euro area has been highly asymmetric. For example, the effects of Chinese competition or of integration with Central and Eastern Europe have been quite different, because of the different models of specialization of the European countries (see also Dieppe et al., 2012)..$^{2}$

Our analysis moves precisely from these considerations, looking at one specific asymmetry in the international trade linkages of European countries, i.e. their involvement in the international fragmentation of production and in global value chains, which impacts directly on countries' international position and competitiveness. We therefore anticipate that European countries' involvement in the IFP should be assessed as a potential medium-term determinant contributing to their current account. Here we first measure each country's level of IFP, using a variation of the index that has become standard in the literature, the "narrow offshoring" index. ${ }^{3}$ The aggregate

\footnotetext{
${ }^{2}$ Even less traditional analyses of CA imbalances in the euro area consider the issue of the relative competitiveness of countries as a crucial one. See Collignon (2013). Another explanation of within-EU current account imbalances that is worth mentioning is the allocation of resources toward non-tradable sectors (housing boom) highlighted by Giavazzi and Spaventa (2010).

${ }^{3}$ This index is based on the so-called "narrow offshoring", commonly used in the literature to measure the weight of imported intermediate inputs belonging to sector $j$ and employed for production in the same sector, originally introduced by Feenstra and Hanson
} 
offshoring index is given by the following expression:

$$
\text { OFFIND } D_{i t}=\frac{\sum_{j} \sum_{s} \text { import }_{j s}^{i}}{\sum_{j} \text { input }_{j}^{i}}
$$

where $i$ is the reporting country (in our case, a member state of the EU), $t$ is time, $s$ is the partner from which a country imports intermediate goods, $j$ is a country's intermediate goods sector.

The data used to build our measure of IFP (or intermediate goods trade) come from the WIOD recently released within a project founded by the Seventh Framework Programme of the European Commission. The database is built on national accounts statistics, national input-output tables and national supply-use tables for 40 countries (among which are the EU27 countries), for the period 1995-2011. In particular, it provides domestic and international input-output flows at two-digit industries. ${ }^{4}$ Even if imperfect, this measure is considered a good starting point to assess a country's involvement in the global value chain. ${ }^{5}$

As shown in Table 1, the offshoring index presents relevant variations across EU members. The different values of the index can be the result of a combination of factors: the extent of international fragmentation of production used by local firms and the involvement of a country in international production chains, the position of a country within such international production chains, and the dependence of its manufacturing system on imported inputs. Therefore these indexes should be interpreted with caution. In any case, the level of IFP measured through this index appears to be sizeable for all the EU countries, being on average about $30 \%$ and with a slight increasing trend over the past decade for most countries. Table 1 also reports the offshoring index computed using intermediate inputs imported from high-income countries only (most of them European), and from lowincome countries only. ${ }^{6}$ It appears that for the EU countries in our sample,

(1996), and subsequently improved thanks to the use of input - output tables for imports. We take the aggregate measure by summing up by sectors and by partners, so that our numerator is the sum of the value of all intermediate goods imported by all intermediate goods' sectors of country $i$ from all sectors of all partners' countries $s$ (including the Rest of the World aggregate), while at the denominator we have the total value of all intermediate inputs used in production in all sectors of country $i$.

${ }^{4}$ For a detailed description of the dataset, see Stehrer (2012).

${ }^{5}$ One aspect that this index does not allow us to capture is the upstream or downstream position of a country in the production chain, which might be relevant in affecting its overall international position. See Antras et al. (2012).

${ }^{6}$ The sum of the offshoring index from the two groups does not coincide with the total index of offshoring, as in the WIOD database a share of imported inputs does not have a defined geographical origin and it comes from the "rest of the world". See Appendix 5.1. 
intermediate inputs are imported mainly from high-income countries, but the relative importance of the two groups also varies.

This general observation on the relevance of IFP for the European countries is substantiated by the second indicator we used to assess this phenomenon. The availability of input - output tables allowing the use of domestic and imported intermediate inputs in production to be separated makes it possible to compute the domestic and foreign contribution to value added in final goods (see Koopman et al., 2014). According to Johnson (2014) and Bems (2014) trade flows measured in gross and value added terms could be differently related to the external position of a country. Following this intuition, by using the WIOD database and following Koopman's methodology, we decomposed domestic and foreign value added in EU countries' gross exports. ${ }^{7}$ The results of this decomposition are reported in Table 2. Confirming what is already apparent in the offshoring indexes, the foreign value added content of gross exports (FVA) also shows high variations across countries, and the change over time did not follow the same trend for each country: Italy and Germany experienced a strong growth in the foreign content of exports, while countries like Greece and Portugal experienced a reduction. The share of foreign value added in export is unsurprisingly very high, especially for the smaller EU countries, but it is close to one quarter or one fifth for the largest EU members also. Overall the foreign value added content of the euro area exports was above $20 \%$ in the recent years. This indicator is correlated with the offshoring index, but it should convey more precise information on the involvement in global value chains, being computed specifically on exports and taking into account re-imports.

Recent analyses using similar decomposition techniques show that the involvement of European countries in international production chains remains quite strong at the European regional level (Amador et al., 2013). On average, well over $10 \%$ of the value added in exports of a euro area country is originated in another euro area country, and the share increases to over $15 \%$ considering value added coming from all EU members. For euro area countries, in the past decade supply linkages within the euro area maintained their relative importance, with little geographic re-orientation toward other parts of the world.

These strong intra- and extra-EU production linkages have certainly affected the import and export flows of EU countries and their trade balance. Countries' international competitiveness, in addition to macroeconomic factors, is in fact strictly related to countries' specialization and to the organization of production. International fragmentation of production, by af-

\footnotetext{
${ }^{7}$ See Appendix 5.3.
} 
fecting the organization of production (Grossman and Rossi-Hansberg, 2008; Timmer et al., 2013), can affect competitiveness, both through direct cost effects (Baldone et al., 2002), or through productivity effects (Grossman and Rossi-Hansberg, 2008; Halpern et al., 2011), or through a "quality" channel (Verhoogen, 2008; Kugler and Verhoogen, 2012). This is why we proceed to analyze the relationship between CA balance and IFP.

\section{Estimating the relationship between offshoring and trade balances}

\subsection{The empirical framework}

We use two sources of data. As mentioned, our measures of international fragmentation of production, i.e. the indexes described in the previous section, are based on the recently released WIOD database. In the first set of regressions, we have considered an aggregate index of offshoring for each EU27 reporting country, so the index is given by the ratio of the total value of intermediate goods imported by all sectors of country $i$ from all partners $s$, i.e. the total value of intermediate goods imported by country $i$, over the total use of intermediate goods by country $i$ at time $t$. Since we are interested in the relationship between a country's involvement in the global value chain, proxied by the offshoring index, and a country's current account balance, we also need data on macroeconomic variables for the EU countries to estimate a standard model of current account determination, and we use national accounting data provided by Eurostat. We focus on the EU27 countries for the period 1999-2011.

As a first step, we consider a standard empirical model of current account determination (see, for instance, Lane and Milesi-Ferretti, 2012). The following empirical specification is considered

$$
\mathrm{CA}_{\mathrm{it}}=a_{0}+a_{2} \mathrm{X}_{\mathrm{it}}+u_{i t}
$$

where the dependent variable is the country $i$ 's current account balance in goods and services ${ }^{8}$ at time $t$ expressed as the ratio to GDP, and $X_{i t}$ is a vector of explanatory variables. We follow the literature on medium-term

\footnotetext{
${ }^{8}$ In our sample, the current account balance in goods and services is highly correlated with the total current account, but for our purposes, considering trade in goods and services only provides a better indicator of a country's external position. In the rest of the paper, by current account we mean the current account in goods and services. Nevertheless, the results for the total current account, including income flows and transfers, confirm the ones presented and they are available from the authors upon request.
} 
current account determination (Chinn and Prasad,2003; Ca' Zorzi, Chudik, Dieppe, 2012; Lane and Milesi-Ferretti, 2012) in considering the following potential determinants of current accounts:

- as for demographic variables, we consider the total population and the population growth rate, which is expected to have a negative sign as a positive demographic trend tends to increase aggregate consumption in the short run; we also include the old-age dependency ratio as the ratio of people older than 65 years over the population aged between 15 and 64 , the sign of which is also expected to be negative since a country with a relatively high share of an economically dependent population is expected to have a lower level of national savings, and therefore a lower CA balance;

- fiscal balance, as a percentage of GDP; several recent models show potential mechanisms through which a departure from the Ricardian equivalence is possible and predict a positive relationship between government budget balances and current account in the medium term, e.g. the "twin deficits" debate $; 9$

- real GDP's growth rate, capturing catching-up factors, is usually expected to have a negative sign, since the higher the real GDP growth, the higher the income expected in the future, and the higher the current consumption;

- income per capita, measured as GDP in purchasing power standard (PPS) per inhabitant, again capturing catching-up factors; this variable is expected to have a positive relationship with the CA balance since the lower the income per capita the larger the current account deficits expected in the catching-up process;

- investment, i.e. gross capital formation as a share of GDP, is usually expected to be negatively associated with the CA balance since the higher the current investment the higher the growth rate expected in the future, on the one hand, and the higher the current demand, on the other hand, both factors worsening the CA balance;

- real effective exchange rate (lagged) as a measure of a country's competitiveness is expected to have a positive relationship with the CA balance (the sign of the coefficient should be negative in our case, given the adopted definition of the exchange rate);

\footnotetext{
${ }^{9}$ See also Florio and Ghiani (2015) on this point.
} 
- net foreign assets (expressed as a share of the GDP, lagged), which according to the literature should have a negative sign: the higher the foreign debt (the lower the NFA) the better should be the current account in the following period;

- energy products balance (values of net export of energy products ${ }^{10}$ as a share of GDP) is usually expected to have a positive relationship with the CA balance.

In the second step, we include in the model the offshoring index as computed in equation (1) or the FVA measure (see Appendix 5.3) to check the relationship between a country's current account over GDP and its involvement in the global value chain, and whether such a relationship is robust to the inclusion of all the regressors usually considered as the main determinants of current account balances, i.e. the regressors considered in equation (2) listed above. We then run the following regression

$$
\mathrm{CA}_{i \mathrm{t}}=a_{0}+a_{1} \text { IFP }_{\mathrm{it}}+a_{2} \mathrm{X}_{\mathrm{it}}+u_{i t}
$$

where the dependent variable is, as in equation (2), country $i$ 's CA balance at time $t$ expressed as a ratio to GDP, $X_{i t}$ is the vector of explanatory variables as in equation (2) and $I F P_{i t}$ is our measure of international fragmentation of production.

As anticipated in the introduction, there is no a priori expected sign for the IFP variable, as a country's participation in the global value chain could have different effects on the current account. In particular, we have mentioned i) the re-importing effect, potentially negatively related with the current account, ii) the competitiveness-enhancing effect, which can be further decomposed in terms of cost/efficiency competitiveness and quality/non-price competitiveness, all potentially positively related with the current account, and, last but not least, iii) the income channel, with ambiguous effects on the CA depending on consequences of IFP on the type of tasks kept domestic and the general equilibrium effects on total production and factors' returns. It is worth noting that by introducing in our empirical model the income per capita and the real effective exchange rate not only do we consider two main determinants of the $\mathrm{CA}$, but we also control for two of the potential channels linking the IFP to the CA, mentioned above.

Going a step further, should a competitive effect be at work, then the characteristics of the partner where offshoring takes place should also matter. To investigate this aspect, in the third step, we split the partners of a country

\footnotetext{
${ }^{10}$ We use the aggregated group G27 - Mineral fuels, mineral oils and products of their distillation; bituminous substances; mineral waxes.
} 
in its international vertical relationships according to their product quality. The higher the partners' product quality, the higher the quality of imported intermediate inputs should be, and therefore the higher the quality of final goods produced by a country (Kugler-Verhoogen, 2012; Colantone and Crinó, 2014), which will in turn positively affect its competitiveness.

The first measure that we use to proxy the product quality of the partners is an indirect one, i.e. the income per capita, following previous contributions according to which income per capita is positively related with the quality of goods produced, consumed and exported by a country (Verhoogen, 2008; Epifani and Crinó, 2012). We split the partners according to the GDP per capita in PPP in 1998 (Source: IMF). We also consider an alternative "direct" measure of a country's product quality recently provided by Hallak and Shott (2010), the "normalized quality index", and we rank the partners according to this index in 1998, to reduce potential endogeneity issues. As underlined by Hallak and Shott (2010), the overlapping in the countries' rankings based on their normalized quality index and on the income per capita is only partial, and therefore it makes sense to use both indicators. ${ }^{11}$

We build two groups of countries, low- and high-, taking the median value of the GDP per capita and the normalized quality index in $1998 .{ }^{12}$ This way we build six new variables on the basis of the type of partners in offshoring. Offind-LI, i.e. offshoring to low-income partners, offind-LQ, i.e. offshoring to low-product quality partners, offind-HI, i.e. offshoring to high-income partners, offind-HQ, i.e. offshoring to high-product quality partners, offindres, i.e. which represent the offshoring to a group of partners that is residual, not classified, in the two rankings. We report in the Appendix (5.1) the list of countries belonging to each group. As underlined by Johnson (2014) and Bems (2014), IFP measured in gross terms and in value added terms conveys different information on a country's participation in the global value chain. We then carry out the analysis above by using the index resulting from our decomposition of value added in export, specifically the share of foreign value added in export, both aggregate and split according to the origin of the imported intermediate inputs (Appendix 5.3).

Finally, if a competitiveness effect is at work, the quality of the domestic market and the segment where a country competes in the foreign market should also matter. Therefore, we carry out the above analysis on two sub-

\footnotetext{
${ }^{11}$ Another reason why we choose to rely on both the rankings is that in both cases some countries are excluded from the partners splitting, and enter a residual group, because there is non-overlapping with the WIOD data (see Appendix 5.1). By using two indicators we are more comfortable in claiming that results do not depend on the residual group.

${ }^{12}$ For robustness, we have carried out our analysis also considering 2003, and the results do not change.
} 
samples of countries: EU13 (mature economies) and Eastern EU countries. ${ }^{13}$ The results are presented in the next section.

\subsection{Results}

In Column 1 of Table 3, we analyze the main macroeconomic determinants of the CA balances in goods and services for the EU27 countries over the period 1999 - 2011, by carrying out the estimation of the model in equation (2), with country and time fixed effects included. ${ }^{14}$ Our results show that investment, population (both stock and growth), and net foreign assets are significantly and negatively related to EU countries' current accounts as expected, while fiscal balance and income per capita are positively related to the CA. ${ }^{15}$ These results are in line with what is expected according to the previous literature, as reported in Section 3.1, and in general they fit well a catching up explanation of external imbalances (Blanchard and Giavazzi, 2002; Chinn and Prasad, 2003; Schmitz and von Hagen, 2011).

In Column 2 we show the estimates of model (3), where we also include among the current account determinants our main variable of interest, i.e. the offshoring index in equation (1). The main results reported for the estimation of the previous model still hold. The relationship of the offshoring index with the current account balances observed in model (3) is not significant. This is still the case in Column 3, reporting the results of our preferred specification, where we estimate model (3) by accounting for both time and spatial correlation in the error terms, by correcting standard errors following Driscoll and Kraay (1998). ${ }^{16}$ This is particularly relevant since we are considering EU27 countries which in the decade covered have been involved in a process of economic and policy integration. As for our main variable of interest, i.e. the offshoring index, it is still insignificant.

This result changes when we include the offshoring indexes split according to the type of partners. As mentioned in the section above we split the partners according to their product quality level proxied by two different indexes: the GDP per capita and a more sophisticated measure of a country's product quality, the "normalized quality index" recently introduced by Hal-

\footnotetext{
${ }^{13}$ See Appendix 5.2.

${ }^{14}$ Hausman's specification test has been run rejecting the null hypothesis; therefore we rely on the FE specification.

${ }^{15}$ Our analysis, by including country fixed effects, is exploiting within-country (over time) variability, which is likely to be low for the group of EU27 countries in the period considered, especially compared to larger sample cross-country analyses. This may explain why some of the determinants of current account are not significant in our results.

${ }^{16}$ Driscoll and Kraay standard errors are also robust to heteroskedasticity.
} 
lak and Shott (2010). In both cases we rank countries with respect to the median value in 1998, which allows the countries' ranking to be exogenous with respect to our analysis, starting in 1999.

In Column 1 of Table 4, countries are split according to the first index of quality, i.e. GDP per capita. Our variables of interest are offind-LI and offind-HI, their coefficients capturing the different effect on the current account of offshoring to low-income partners / high-income partners with respect to using input produced domestically. In Column 2 of Table 4, countries are split according to the Hallak and Shott (2010) index of quality. In this case our variables of interest are offind-LQ and offind-HQ, their coefficients capturing the different effect on the current account of offshoring to low-product quality partners / high-product quality partners with respect to using input produced domestically.

In both cases the indexes turn out to be significant, at the $1 \%$ level, with a negative sign and a positive sign when offshoring to low-income/lowproduct quality partners and offshoring to high-income/high-product quality partners, respectively, are taken into account. In terms of magnitude, an increase of 1 percentage point (p.p.) of the offshoring to low-income partners is related to a decrease of 0.72 p.p. in the CA, while an increase of 1 p.p. of the offshoring to high-income partners increases the CA by 0.18 p.p. Similarly, an increase of 1 p.p. of the offshoring to low-product quality partners is related to a decrease of 0.75 p.p. in the CA, while an increase of 1 p.p. of the offshoring to high-product quality partners increases the CA by 0.19 p.p.

The relationship is robust to the inclusion of all the medium-term determinants of CA considered in the literature listed in the previous section. This suggests that offshoring is producing some significant additional effects. As mentioned before, those effects could occur through several channels, namely the re-importing effect, potentially negatively related with the current account, the competitiveness-enhancing effect, which can be further decomposed in terms of cost/efficiency competitiveness and quality/non-price competitiveness, all potentially positively related with the current account, and the income channel. We claim that the channels captured by our coefficient are likely to be the "accounting" channel due to re-importing and the quality channel enhancing competitiveness, since in our analysis price competitiveness and income effects are controlled for by lagged REER and by per capita GDP, respectively.

The negative sign of offshoring to low-income/low-product quality countries may be capturing the fact that when countries offshore to low-income/lowproduct quality partners the accounting effect overcomes the competitiveness effect, the latter being weakened by a lower quality of final goods incorporating lower-quality inputs (Kugler-Verhoogen, 2012). 
The opposite happens when countries offshore to high-income/high-product quality partners. In this case the competitiveness effect prevails.

Instead, the overall offshoring index computed aggregating all the partners to which a country offshores, was not significant owing to offshoring having opposite effects according to the "quality" of the country of destination.

In Table 5 we present the results when the analysis is carried out considering as the main variable of interest the foreign value added content of a country's export, for all partners (Column 1), and split by type of partner (Column 2 and 3). ${ }^{17}$ The results are aligned with those obtained considering the offshoring index (Table 4,): the overall measure of foreign value added in a country's export is not significant (Column 1) while if foreign value added originates from a low-income/low-product quality partner it significantly and negatively affects the CA (Table 5, Column 2 and Column 3, respectively). As for the magnitude, the effect is now smaller than in the case of the offshoring index; an increase of 1 p.p. of the foreign value added from low-income (low-product quality) partners is related to a decrease of 0.53 p.p. (0.50 p.p.) in the CA. Unlike the results obtained with the offshoring index, in this case the relationship between foreign value added from a highincome/high-product quality partner with the current account is positive, but not statistically significant.

In order to further test the "competitiveness effect" related to IFP, we estimate the same model over the sub-sample of Central and Eastern EU countries and EU "advanced" countries, by considering both the offshoring index (Table 6), and the foreign value added index (Table 7). We expect the negative (positive) effect to be larger (smaller) in countries where the domestic market is more likely to absorb lower-quality goods and in countries trading mostly in the low-quality segment of the foreign markets.

When considering the sub-samples Eastern EU countries and EU13 the results for offshoring (Table 6) and foreign valued added (Table 7) are aligned. Interestingly enough, among the EU Eastern countries, both offshoring and incorporating foreign valued added from low-income/low-product quality partners significantly and negatively affect the CA, the magnitude of the coefficients being larger than in the whole sample. On the other hand, among the EU13 the relationship is not significant. By contrast, among the EU13, both offshoring and incorporating foreign valued added from high-income/highproduct quality partners significantly and positively affect the CA, again the magnitude of the coefficients being larger than in the whole sample, while

\footnotetext{
17 The estimation method of model (3) with this new specification is the same as in Column 3 of Table 3 and in Column 1 and 2 of Table 4.
} 
among the EU Eastern countries the relationship is not significant. These results suggest that the quality of domestic demand and production also matter. Moreover, EU Eastern countries buy and sell more than the EU-13 in the low-quality segment of the foreign markets, therefore the negative effect of producing low-quality goods is more relevant in EU Eastern countries than in EU13.

\section{Conclusion}

In this paper we make a first attempt to explore the potential relationship between the current account imbalances of the EU countries and the phenomenon of the international fragmentation of production within Europe. We build two indicators of countries' involvement in IFP and in global value chains: an offshoring index, and the share of foreign value added in gross exports, both obtained from the WIOD database. We use these indicators to test empirically this relationship for the EU countries in the period 19992011.

Our results show that IFP is indeed a relevant component of EU countries' CA. The CA in EU countries worsens the higher the offshoring to low-income/low-product quality countries, i.e. the lower the production using high-quality inputs. This evidence suggests that the potentially negative effect of importing intermediate inputs on the current account is not compensated by the potentially positive effect of gaining competitiveness by offshoring when countries import low-quality inputs. On the other hand, the higher the offshoring to high-income/high-product quality countries the more the CA improves, suggesting that incorporating high-quality imported inputs into production allows the competitiveness channel to prevail.

Our results are robust to the inclusion of standard medium-term CA determinants, to different indicators of IFP, to different rankings based on different countries' product quality indexes, and are not driven by outliers (countries, years, partners).

In particular, results are not symmetric for EU Eastern countries and EU13. The negative relationship between $\mathrm{CA}$ and offshoring to low-income/lowproduct quality countries holds for EU Eastern countries, but not for EU-13, suggesting that both the quality of domestic demand and the segment of competition (low- vs. high-quality) in the foreign markets matter. By contrast, the positive relationship between $\mathrm{CA}$ and offshoring to high-income/highproduct quality countries holds for EU-13, but not for EU Eastern countries.

As a general conclusion, our results suggest that a country's involvement in the global value chain negatively affects its external position only if the 
country buys from low-product quality partners. Otherwise the net effect is positive.

From a policy perspective we could conclude that what is relevant is the ability of a country to enhance its competitiveness through offshoring by "selecting" the right type of partners, which is probably also driven by the determinants of offshoring, i.e. learning from partners, importing technology and knowledge versus pure cost saving. It is worth noting, nevertheless, that additional considerations are needed to evaluate the overall welfare effects of offshoring, as the effects on a country's external position are only a part of the consequences of this phenomenon. 


\section{References}

[1] Amador, J., Stehrer, R., R. Cappariello, (2014). "Global Value Chains: A View from the Euro Area", Banco de Portugal, Economics and Research Department, W201412.

[2] Antras, P., Chor, D., Fally, T., R. Hillberry, (2012). "Measuring Upstreamness of Production in Trade Flows", American Economic Review Paper and Proceedings, 102 (3), 412-416.

[3] Arkolakis, C. and A. Ramanarayanan, (2009). "Vertical Specialization and International Business Cycle Synchronization"', Scandinavian Journal of Economics 111(4), 655680.

[4] Baldone, S., Sdogati, F., L. Tajoli, (2002). "Moving to Central-Eastern Europe: Fragmentation of Production and Competitiveness of the European Textile and Apparel Industry", Rivista di Politica Economica, 92(1), 209-282.

[5] Baldone, S., Sdogati, F., L. Tajoli, (2007). "On Some Effects of International Fragmentation of Production on Comparative Advantages, Trade Flows and Income of Countries", The World Economy, 30(11), 1726-1779.

[6] Belke, A. and C. Dreger, (2013). "Current Account Imbalances in the Euro Area: Does Catching up Explain the Development?", Review of International Economics, 21(1), 617.

[7] Bems, R., (2014). "Intermediate Inputs, External Rebalancing and Relative Price Adjustment", Journal of International Economics, forthcoming.

[8] Blanchard, O. and F. Giavazzi, (2002). "Current Account Deficits in the Euro Area: The End of the Feldstein-Horioka Puzzle?", Brookings Papers on Economic Activity, (2), 147-209.

[9] Ca' Zorzi, M., Chudik, A., and A. Dieppe, (2012). "Thousands of Models, one story. Current account imbalances in the global economy", Journal of International Money and Finance, 31, 1319-1338.

[10] Chen, R., Milesi-Ferretti G.-M., and T. Tressel, (2012). "External imbalances in the Euro Area", IMF Working Paper WP/12/236.

[11] Cheung, Y.-W., Chinn, M. and Qian, X., (2012). "Are Chinese Trade Flows Different?", Journal of International Money and Finance, 31(8)21272146. 
[12] Chinn, M. D. and E. S. Prasad, (2003). "Medium-term determinants of current accounts in industrial and developing countries: an empirical exploration," Journal of International Economics, 59(1), 47-76.

[13] Colantone, I. and R. Crinó, (2014). "New Imported Inputs, New Domestic Products", Journal of International Economics, 92(1), 147-165.

[14] Collignon, S., (2013). "Macroeconomic imbalances and competitiveness in the Euro Area", Transfer: European Review of Labour and Research, $19(1), 63-87$.

[15] Costinot, A., Vogel, J. and S. Wang, (2013). "An Elementary Theory of Global Supply Chain", Review of Economic Studies, 80, 109144.

[16] Coudert, V., Couharde, C. and V. Mignon, (2013). "On Currency Misalignments within the Euro Area", Review of International Economics, 21(1), 3548.

[17] Crinó, R. and P. Epifani, (2012). "Productivity, Quality and Export Behavior", Economic Journal, 122(565), 1206-1243

[18] Crozet, M., Head, K. and T. Mayer, (2012). "Quality sorting and trade: Firm-level evidence for French wine", Review of Economic Studies 79(2), 609-644.

[19] Daudin, G., Rifflart, C., D. Schweisguth, (2011). "Who Produces for Whom in the World Economy?", Canadian Journal of Economics, 44 (4), 1403-1437.

[20] Deardorff, A.V. (2001), "Fragmentation in Simple Trade Models", North American Journal of Economics and Finance, 12, 121-37.

[21] Deardorff, A.V. (2001), "Fragmentation across Cones", in S.W. Arndt and H. Kierzkowski (eds.) Fragmentation. New Production Patterns in the World Economy, Oxford University Press, 35-51.

[22] Deardorff, A.V. (2005), "Ricardian Comparative Advantage with Intermediate Inputs", North American Journal of Economics and Finance, 16, 11-34.

[23] Dieppe, A. et al. (2012), "Competitiveness and External Imbalances within the Euro Area", European Central Bank Occasional Paper Series no. 139 . 
[24] Driscoll J.C. and Kraay A.C. (1998) Consistent covariance matrix estimation with spatially dependent panel data, The Review of Economics and Statistics, 80 (4), 549-560.

[25] Elms, D.K. and P. Low (eds.) (2013). "Global value chains in a changing world", WTO Publications.

[26] Egger, H. and P. Egger (2005). "The Determinants of EU Processing Trade", The World Economy, 28 (2), 147-68.

[27] Escaith, H., Lindenberg, N. and S. Miroudot (2010). "International Supply Chains and Trade Elasticity in Times of Global Crisis", Staff W.P. ERSD-2010-08.

[28] Falzoni, A. and L. Tajoli, (2015). "International Fragmentation of Production and Trade Volatility: an Analysis for the European Countries". Modern Economy, forthcoming.

[29] Falvey, R. and H. Kierzkowski, (1987). "Product Quality, Intra-Industry Trade and (im)perfect competition", in (H. Kierzkowski, ed.), Protection and Competition in International Trade, 495-511, Oxford: Basil Blackwell.

[30] Flam, H. and E. Helpman, (1987). "Vertical Product Differentiation and and North-South Trade", American Economic Review, vol. 77(5), 810-822.

[31] Feenstra, R. and G. Hanson, (1996). "Globalization, outsourcing and wage inequality", American Economic Review, 86(2), 240-245.

[32] Feenstra, R.C. and J. Romalis, (2014). "International Prices and Endogenous Quality", Quarterly Journal of Economics, 129(2), 477-527.

[33] Florio, A. and G. Ghiani, (2015). "The twin deficit behavior across booms and busts: a Markov-switching analysis ", unpublished.

[34] Giavazzi, F. and L. Spaventa, (2010). "Why the Current Account May Matter in a Monetary Union: Lessons from the Financial Crisis in the Euro Area", CEPR Discussion Paper No. 8008.

[35] Gopinath, G. and B. Neiman, (2014). "Trade Adjustment and Productivity in Large Crises", American Economic Review, 104(3), 797-783.

[36] Grossman, G. and E. Rossi-Hansberg, (2008). "Trading Tasks: A Simple Theory of Offshoring", American Economic Review, 98(5), 1978-1997. 
[37] Guerrieri, P. and P. Esposito, (2012). "Intra-European Imbalances, Adjustment, and Growth in the Eurozone", Oxford Review of Economic Policy, 28 (3), 532-550.

[38] Guillemette, Y. and D. Turner, (2013). "Policy Options to Durably Resolve Euro Area Imbalances", OECD Economics Department Working Paper no. 1035, OECD Publishing.

[39] Hallak, J. C., (2006). "Product Quality and the Direction of Trade", Journal of International Economics, vol. 68(1), 238-265.

[40] Halpern,L., M. Koren and A. Szeidl (2011). "Imported Inputs and Productivity", unpublished paper.

[41] Hummels, D., J. Ishii, and K. Yi. (2001). "The Nature and Growth of Vertical Specialization in World Trade." Journal of International Economics, 54, 75-96.

[42] Johnson, R. and G. Noguera (2012). "Accounting for Intermediates: Production Sharing and Trade in Value Added", Journal of International Economics, 86 (2), 224-236.

[43] Johnson, R. (2014). "Five Facts about Value Added Exports and Implications for Macroeconomics and Trade Research", Journal of Economic Perspectives, 28 (2), 119-142.

[44] Lane, P.R. and G.M. Milesi-Ferretti (2012). "External adjustment and the global crisis", Journal of International Economics, 88, 252-265.

[45] Levchenko, A. A., Lewis, L.T., and L. L. Tesar (2010). "The Collapse of International Trade during the 2008-2009 Crisis: in Search of the Smoking Gun", IMF Economic Review, 58 (2), 214-253.

[46] Koopman, R., Wang, Z. and Wei, S.J. (2014). "Tracing Value-Added and Double Counting in Gross Exports", American Economic Review, 2014, 104 (2), 459-94.

[47] Kugler, M. and E. Verhoogen, (2012). "Prices, Plant size and Product Quality", Review of Economic Studies, 79, 307339.

[48] Marquez, J. and J. Schindler (2007), "Exchange-rate Effects on China's Trade", Review of International Economics, 15(5), 837-853.

[49] Miroudot, S. and A. Ragoussis (2009), "Vertical Trade, Trade Costs and FDI", OECD Trade Policy W.P. N. 89. 
[50] Obstfeld, M. and K. Rogoff (1998), "Foundations of International Macroeconomics", MIT Press,Cambridge, MA.

[51] Obstfeld, M. and K. Rogoff (2007), "The Unsustainable U. S. Current Account Position Revisited". In R. Clarida ed., G7 Current Account Imbalances: Sustainability and Adjustment, NBER Chapters, NBER Inc, 339-376.

[52] Razin, A. (1995), "The Dynamic-Optimizing Approach to the Current Account: Theory and Evidence"'. In P. Kenen ed., Understanding Interdependence: The Macroeconomics of the Open Economy. Princeton University Press. Princeton.

[53] Schmitz, B. and J. von Hagen (2011), "Current account imbalances and financial integration in the euro area", Journal of International Money and Finance 30 (8), 1676-1695.

[54] Stehrer, R. (2012), "Trade in Value Added and the Value Added in Trade", WIOD W.P. N. 8.

[55] Timmer, M. P., B. Los, R. Stehrer and G. J. de Vries (2013), "Fragmentation, Incomes and Jobs. An analysis of European competitiveness", Economic Policy, vol. 28(76), 613-61.

[56] Timmer, M. P., A. A. Erumban, B. Los, R. Stehrer and G. J. de Vries (2014), "Slicing Up Global Value Chain", Journal of Economic Perspectives, vol. 28(2), 99-118.

[57] Thorbecke, W. and G. Smith (2010), "How Would an Appreciation of the Renminbi and Other East Asian Currencies Affect Chinas' Exports? ", Review of International Economics, vol. 18(1), 95-108.

[58] Unctad (2013), "Global Value Chain and Development".

[59] Verhoogen, E. (2008). "Trade, Quality Upgrading and Wage Inequality in the Mexican Manufacturing Sector", The Quarterly Journal of Economics, vol. 123(2), 489-530.

[60] Yi, K.-M. (2003), "Can Vertical Specialization Explain the Growth of World Trade?," Journal of Political Economy, vol. 111(1), 52-102. 
Table 1: Offshoring in EU countries (average index for 1999-2011)

\begin{tabular}{lccc}
\hline Country & $\begin{array}{c}\text { Offshoring index } \\
\text { (total) }\end{array}$ & $\begin{array}{c}\text { Offshoring index } \\
\text { to high-income partners }\end{array}$ & $\begin{array}{c}\text { Offshoring index } \\
\text { to low-income partners }\end{array}$ \\
\hline Luxembourg & 60.58 & 55.82 & 2.87 \\
Malta & 46.56 & 34.13 & 4.75 \\
Ireland & 45.83 & 37.87 & 3.79 \\
Hungary & 41.42 & 26.49 & 7.91 \\
Lithuania & 39.32 & 13.60 & 7.45 \\
Belgium & 36.97 & 28.85 & 3.92 \\
Slovakia & 36.24 & 16.30 & 10.48 \\
Cyprus & 34.68 & 18.50 & 7.35 \\
Netherlands & 33.84 & 20.90 & 4.31 \\
Estonia & 33.78 & 17.52 & 6.38 \\
Slovenia & 32.79 & 22.25 & 4.94 \\
Bulgaria & 31.23 & 13.44 & 8.77 \\
Austria & 30.39 & 19.29 & 5.96 \\
Czech Rep. & 30.00 & 18.98 & 6.59 \\
Denmark & 29.83 & 21.67 & 4.22 \\
Greece & 27.66 & 16.48 & 3.59 \\
Sweden & 26.70 & 18.15 & 3.46 \\
Latvia & 26.17 & 12.25 & 7.47 \\
Romania & 25.50 & 13.85 & 5.89 \\
Finland & 23.50 & 13.84 & 3.85 \\
Poland & 22.75 & 14.52 & 3.67 \\
Portugal & 22.32 & 16.02 & 2.00 \\
Germany & 21.58 & 12.56 & 4.87 \\
Spain & 17.78 & 10.88 & 2.69 \\
France & 17.04 & 11.42 & 1.98 \\
United Kingdom & 16.73 & 11.51 & 2.16 \\
Italy & 15.82 & 8.39 & 2.26 \\
\hline Notes. The & afta & \\
\hline
\end{tabular}

Notes. The offshoring index is computed for each year as in (1) and we computed the simple average for the years 1999-2011. The partners' splitting is reported in Appendix 5.1 .

Source: Our elaborations on WIOD database. 
Table 2: Foreign Value Added in Export in EU countries (average index for 1999-2011)

\begin{tabular}{lccc}
\hline Country & $\begin{array}{c}\text { Foreign Value Added } \\
\text { (total) }\end{array}$ & $\begin{array}{c}\text { Foreign Value Added } \\
\text { (High-income partners) }\end{array}$ & $\begin{array}{c}\text { Foreign Value Added } \\
\text { (Low-income partners) }\end{array}$ \\
\hline Luxembourg & 59.27 & 53.41 & 3.36 \\
Hungary & 45.63 & 30.10 & 8.44 \\
Malta & 44.66 & 31.88 & 5.11 \\
Slovakia & 44.52 & 23.40 & 10.29 \\
Ireland & 42.46 & 34.60 & 3.76 \\
Czech Rep. & 42.02 & 27.16 & 8.25 \\
Belgium & 41.62 & 30.44 & 4.83 \\
Estonia & 39.98 & 22.08 & 7.20 \\
Slovenia & 37.98 & 25.57 & 5.70 \\
Bulgaria & 37.16 & 16.00 & 8.64 \\
Netherlands & 34.40 & 20.27 & 4.52 \\
Lithuania & 34.39 & 11.86 & 5.03 \\
Denmark & 32.88 & 22.88 & 4.95 \\
Austria & 30.74 & 19.86 & 5.47 \\
Sweden & 30.30 & 20.08 & 4.02 \\
Portugal & 29.60 & 20.79 & 3.22 \\
Poland & 29.44 & 18.90 & 4.55 \\
Finland & 29.21 & 16.68 & 5.77 \\
Cyprus & 28.13 & 19.94 & 2.40 \\
Greece & 27.55 & 17.77 & 6.68 \\
Latvia & 27.49 & 13.80 & 5.36 \\
Romania & 27.19 & 15.74 & 3.98 \\
Spain & 26.55 & 15.78 & 3.31 \\
France & 24.93 & 16.50 & 5.13 \\
Germany & 23.87 & 13.95 & 3.46 \\
Italy & 22.29 & 12.34 & 2.58 \\
United Kingdom & 18.60 & 12.34 & \\
Notes & and & & \\
\hline
\end{tabular}

Notes. The Foreign Value Added in a country's export is computed as in Koopmans et al. (2012) for each year and we computed the simple average for the years 1999-2011. The partners' splitting is reported in Appendix 5.1.

Source: Our elaborations on WIOD database. 
Table 3: Models of Current Account Balance determinants

\begin{tabular}{|c|c|c|c|}
\hline & (1) & $(2)$ & (3) \\
\hline dependency ratio & $\begin{array}{c}0.005 \\
(0.283)\end{array}$ & $\begin{array}{c}0.005 \\
(0.290)\end{array}$ & $\begin{array}{c}0.005 \\
(0.154)\end{array}$ \\
\hline fiscal balance & $\begin{array}{c}0.240^{* * *} \\
(0.053)\end{array}$ & $\begin{array}{c}0.239 * * * \\
(0.052)\end{array}$ & $\begin{array}{c}0.239 * * * \\
(0.026)\end{array}$ \\
\hline gdp growth & $\begin{array}{c}0.039 \\
(0.092)\end{array}$ & $\begin{array}{c}0.058 \\
(0.101)\end{array}$ & $\begin{array}{c}0.058 \\
(0.045)\end{array}$ \\
\hline gdp per capita & $\begin{array}{c}0.870^{* * *} \\
(0.187)\end{array}$ & $\begin{array}{c}0.847^{* * *} \\
(0.195)\end{array}$ & $\begin{array}{c}0.847^{* * *} \\
(0.112)\end{array}$ \\
\hline investment & $\begin{array}{c}-0.925 * * * \\
(0.095)\end{array}$ & $\begin{array}{c}-0.934^{* * *} \\
(0.096)\end{array}$ & $\begin{array}{c}-0.934^{* * *} \\
(0.055)\end{array}$ \\
\hline lagged reer & $\begin{array}{c}0.008 \\
(0.039)\end{array}$ & $\begin{array}{c}0.004 \\
(0.039)\end{array}$ & $\begin{array}{c}0.004 \\
(0.014)\end{array}$ \\
\hline total population & $\begin{array}{c}-0.430^{*} \\
(0.211)\end{array}$ & $\begin{array}{c}-0.430^{*} \\
(0.211)\end{array}$ & $\begin{array}{c}-0.430 * * * \\
(0.069)\end{array}$ \\
\hline population growth & $\begin{array}{c}-0.258^{*} \\
(0.133)\end{array}$ & $\begin{array}{c}-0.223 \\
(0.143)\end{array}$ & $\begin{array}{c}-0.223^{* * *} \\
(0.067)\end{array}$ \\
\hline lagged NFA & $\begin{array}{c}-0.034^{* * *} \\
(0.008)\end{array}$ & $\begin{array}{c}-0.034^{* * *} \\
(0.007)\end{array}$ & $\begin{array}{c}-0.034^{* * *} \\
(0.005)\end{array}$ \\
\hline energy balance & $\begin{array}{c}-0.101 \\
(0.244)\end{array}$ & $\begin{array}{c}-0.119 \\
(0.263)\end{array}$ & $\begin{array}{c}-0.119 \\
(0.094)\end{array}$ \\
\hline offind & & $\begin{array}{l}-0.062 \\
(0.118)\end{array}$ & $\begin{array}{l}-0.062 \\
(0.056)\end{array}$ \\
\hline R-squared & 0.7705 & 0.7716 & 0.7716 \\
\hline $\mathrm{N}$ & 314 & 314 & 314 \\
\hline
\end{tabular}

$* \mathrm{p}<0.10, * * \mathrm{p}<0.05, * * * \mathrm{p}<0.01$

Notes. Dependent variable: Current Account (goods and services) balance as a ratio to GDP. All the variables considered are in percentage points, with the exception of the GDP per capita which is in thousands and the total population which is in millions. All models include year and country fixed effects. Standard errors in models (1), (2) are clustered by country. In column (3) Driscoll-Kraay standard errors, which are robust to general forms of spatial correlation, are reported. (a): within R-squared. 
Table 4: Models of Current Account Balance determinants: Offshoring by type of partners

\begin{tabular}{|c|c|c|}
\hline & (1) & $(2)$ \\
\hline dependency ratio & $\begin{array}{c}-0.063 \\
(0.141)\end{array}$ & $\begin{array}{c}-0.055 \\
(0.132)\end{array}$ \\
\hline fiscal balance & $\begin{array}{c}0.265^{* * *} \\
(0.031)\end{array}$ & $\begin{array}{c}0.254^{* * *} \\
(0.029)\end{array}$ \\
\hline gdp growth & $\begin{array}{c}0.040 \\
(0.047)\end{array}$ & $\begin{array}{c}0.041 \\
(0.044)\end{array}$ \\
\hline gdp per capita & $\begin{array}{c}0.872^{* * *} \\
(0.114)\end{array}$ & $\begin{array}{c}0.884^{* * *} \\
(0.118)\end{array}$ \\
\hline investment & $\begin{array}{c}-0.906^{* * *} \\
(0.047)\end{array}$ & $\begin{array}{c}-0.939^{* * *} \\
(0.047)\end{array}$ \\
\hline lagged reer & $\begin{array}{c}0.022 \\
(0.013)\end{array}$ & $\begin{array}{c}0.009 \\
(0.013)\end{array}$ \\
\hline total population & $\begin{array}{c}-0.654^{* * *} \\
(0.082)\end{array}$ & $\begin{array}{c}-0.550^{* * *} \\
(0.074)\end{array}$ \\
\hline population growth & $\begin{array}{c}-0.199^{* * *} \\
(0.065)\end{array}$ & $\begin{array}{c}-0.212^{* *} \\
(0.083)\end{array}$ \\
\hline lagged NFA & $\begin{array}{c}-0.032^{* * *} \\
(0.005)\end{array}$ & $\begin{array}{c}-0.031^{* * *} \\
(0.005)\end{array}$ \\
\hline energy balance & $\begin{array}{l}-0.120 \\
(0.079)\end{array}$ & $\begin{array}{c}-0.140 \\
(0.095)\end{array}$ \\
\hline offind-LI part. & $\begin{array}{c}-0.728^{* * *} \\
(0.127)\end{array}$ & \\
\hline offind-HI part. & $\begin{array}{c}0.180^{* * *} \\
(0.063)\end{array}$ & \\
\hline offind-res part. & $\begin{array}{c}0.011 \\
(0.070)\end{array}$ & \\
\hline offind-LQ part. & & $\begin{array}{c}-0.756^{* * *} \\
(0.062)\end{array}$ \\
\hline offind-HQ part. & & $\begin{array}{c}0.199 * * * \\
(0.061)\end{array}$ \\
\hline offind-res part. & & $\begin{array}{c}0.012 \\
(0.068)\end{array}$ \\
\hline R-squared (a) & 0.7935 & 0.7959 \\
\hline $\mathrm{N}$ & 314 & 314 \\
\hline
\end{tabular}

$* \mathrm{p}<0.10,{ }^{* *} \mathrm{p}<0.05, * * * \mathrm{p}<0.01$

Notes. Dependent variable: Current Account (goods and services) balance as a ratio to GDP. All the variables considered are in percentage points, with the exception of the GDP per capita which is in thousands and the total population which is in millions. All models include year and country fixed effects. Driscoll-Kraay standard errors, which are robust to general forms of spatial correlation, are reported. (a): within R-squared. 
Table 5: Models of Current Account Balance: Foreign Value Added

\begin{tabular}{|c|c|c|c|}
\hline & (1) & $(2)$ & $(3)$ \\
\hline dependency ratio & $\begin{array}{l}-0.011 \\
(0.159)\end{array}$ & $\begin{array}{c}-0.024 \\
(0.146)\end{array}$ & $\begin{array}{c}-0.033 \\
(0.145)\end{array}$ \\
\hline fiscal balance & $\begin{array}{c}0.240^{* * *} \\
(0.025)\end{array}$ & $\begin{array}{c}0.270^{* * *} \\
(0.029)\end{array}$ & $\begin{array}{c}0.263^{* * *} \\
(0.027)\end{array}$ \\
\hline gdp growth & $\begin{array}{c}0.059 \\
(0.040)\end{array}$ & $\begin{array}{c}0.060 \\
(0.040)\end{array}$ & $\begin{array}{c}0.064^{*} \\
(0.036)\end{array}$ \\
\hline gdp per capita & $\begin{array}{c}0.854^{* * *} \\
(0.110)\end{array}$ & $\begin{array}{c}0.844^{* * *} \\
(0.117)\end{array}$ & $\begin{array}{c}0.861^{* * *} \\
(0.115)\end{array}$ \\
\hline investment & $\begin{array}{c}-0.927^{* * *} \\
(0.058)\end{array}$ & $\begin{array}{c}-0.929 * * * \\
(0.050)\end{array}$ & $\begin{array}{c}-0.944^{* * *} \\
(0.053)\end{array}$ \\
\hline lagged reer & $\begin{array}{c}0.003 \\
(0.012)\end{array}$ & $\begin{array}{c}0.025 \\
(0.017)\end{array}$ & $\begin{array}{c}0.020 \\
(0.015)\end{array}$ \\
\hline total population & $\begin{array}{c}-0.412^{* * *} \\
(0.064)\end{array}$ & $\begin{array}{c}-0.515^{* * *} \\
(0.079)\end{array}$ & $\begin{array}{c}-0.463^{* * *} \\
(0.073)\end{array}$ \\
\hline population growth & $\begin{array}{c}-0.228^{* * *} \\
(0.061)\end{array}$ & $\begin{array}{c}-0.167^{* *} \\
(0.062)\end{array}$ & $\begin{array}{c}-0.176^{* * *} \\
(0.061)\end{array}$ \\
\hline lagged NFA & $\begin{array}{c}-0.032^{* * *} \\
(0.005)\end{array}$ & $\begin{array}{c}-0.031^{* * *} \\
(0.005)\end{array}$ & $\begin{array}{c}-0.030^{* * *} \\
(0.005)\end{array}$ \\
\hline energy balance & $\begin{array}{c}-0.146 \\
(0.110)\end{array}$ & $\begin{array}{l}-0.091 \\
(0.096)\end{array}$ & $\begin{array}{c}-0.106 \\
(0.107)\end{array}$ \\
\hline FVS & $\begin{array}{l}-0.069 \\
(0.075)\end{array}$ & & \\
\hline FVS-LI part. & & $\begin{array}{c}-0.539^{* *} \\
(0.201)\end{array}$ & \\
\hline FVS-HI part. & & $\begin{array}{c}0.054 \\
(0.068)\end{array}$ & \\
\hline FVA-res. part. & & $\begin{array}{c}0.039 \\
(0.061)\end{array}$ & \\
\hline FVS-LQ part. & & & $\begin{array}{c}-0.506^{* * *} \\
(0.165)\end{array}$ \\
\hline FVS-HQ part. & & & $\begin{array}{c}0.082 \\
(0.079)\end{array}$ \\
\hline FVA-res. part. & & & $\begin{array}{c}0.030 \\
(0.060)\end{array}$ \\
\hline R-squared (a) & 0.7719 & 0.7827 & 0.7820 \\
\hline $\mathrm{N}$ & 314 & 314 & 314 \\
\hline
\end{tabular}

Note: Dependent variable: Current Account balance in goods and services as a ratio to GDP. All the variables considered are in percentage points, with the exception of the GDP per capita which is in thousands and the total population which is in millions. All models include year and country fixed effects. Driscoll-Kraay standard errors, robust to general forms of spatial correlation, are reported. (a): within R-squared. 
Table 6: CA determinants in EU-Eastern countries and EU-13. Offshoring index.

\begin{tabular}{|c|c|c|c|c|}
\hline & EU-East. & EU13 & EU-East. & EU13 \\
\hline offind-LI part. & $\begin{array}{c}-0.852^{* * *} \\
(0.098)\end{array}$ & $\begin{array}{c}0.202 \\
(0.449)\end{array}$ & & \\
\hline offind-HI part. & $\begin{array}{c}0.201 \\
(0.115)\end{array}$ & $\begin{array}{c}0.330^{* * *} \\
(0.043)\end{array}$ & & \\
\hline offind-res part. & $\begin{array}{c}0.007 \\
(0.083)\end{array}$ & $\begin{array}{c}0.197^{*} \\
(0.101)\end{array}$ & & \\
\hline offind-LQ part. & & & $\begin{array}{c}-0.860^{* * *} \\
(0.178)\end{array}$ & $\begin{array}{c}0.170 \\
(0.265)\end{array}$ \\
\hline offind-HQ part. & & & $\begin{array}{c}0.183 \\
(0.152)\end{array}$ & $\begin{array}{c}0.427^{* * *} \\
(0.058)\end{array}$ \\
\hline offind-res part. & & & $\begin{array}{l}-0.072 \\
(0.088)\end{array}$ & $\begin{array}{c}0.246^{* * * *} \\
(0.058)\end{array}$ \\
\hline R-squared (a) & 0.8924 & 0.8427 & 0.8899 & 0.8454 \\
\hline $\mathrm{N}$ & 120 & 150 & 120 & 150 \\
\hline
\end{tabular}

${ }^{*} \mathrm{p}<0.10,{ }^{* *} \mathrm{p}<0.05,{ }^{* * *} \mathrm{p}<0.01$

Note: Dependent variable: Current Account balance in goods and services as a ratio to GDP. All the variables considered are in percentage points, with the exception of the GDP per capita which is in thousands and the total population which is in millions. All models include year and country fixed effects. All the set of variables of the previous specification are included. Driscoll-Kraay standard errors, robust to general forms of spatial correlation, are reported. (a): within R-squared. Countries are listed in Appendix 5.2. 
Table 7: CA determinants in EU-Eastern countries and EU13. FVA.

\begin{tabular}{|c|c|c|c|c|}
\hline & EU-East. & EU13 & EU-East. & EU13 \\
\hline FVS-LI part. & $\begin{array}{c}-0.710^{* * *} \\
(0.207)\end{array}$ & $\begin{array}{l}-0.250 \\
(0.372)\end{array}$ & & \\
\hline FVS-HI part. & $\begin{array}{l}0.249^{*} \\
(0.117)\end{array}$ & $\begin{array}{c}0.203^{* *} \\
(0.093)\end{array}$ & & \\
\hline FVS-res. part. & $\begin{array}{c}0.069 \\
(0.062)\end{array}$ & $\begin{array}{c}0.071 \\
(0.109)\end{array}$ & & \\
\hline FVS-LQ part. & & & $\begin{array}{c}-0.591^{* *} \\
(0.235)\end{array}$ & $\begin{array}{c}0.058 \\
(0.222)\end{array}$ \\
\hline FVS-HQ part. & & & $\begin{array}{c}0.278 \\
(0.159)\end{array}$ & $\begin{array}{c}0.212^{* *} \\
(0.079)\end{array}$ \\
\hline FVS-res. part. & & & $\begin{array}{c}0.048 \\
(0.066)\end{array}$ & $\begin{array}{c}0.092 \\
(0.068)\end{array}$ \\
\hline R-squared (a) & 0.8870 & 0.8334 & 0.8842 & 0.8323 \\
\hline $\mathrm{N}$ & 120 & 150 & 120 & 150 \\
\hline
\end{tabular}

${ }^{*} \mathrm{p}<0.10,{ }^{* *} \mathrm{p}<0.05,{ }^{* * *} \mathrm{p}<0.01$

Note: Dependent variable: Current Account balance in goods and services as a ratio to GDP. All the variables considered are in percentage points, with the exception of the GDP per capita which is in thousands and the total population which is in millions. All models include year and country fixed effects. All the set of variables of the previous specification are included. Driscoll-Kraay standard errors, robust to general forms of spatial correlation, are reported. (a): within R-squared. Countries are listed in Appendix 5.2. 
Figure 1: Current Account balance in \% of GDP, 2007

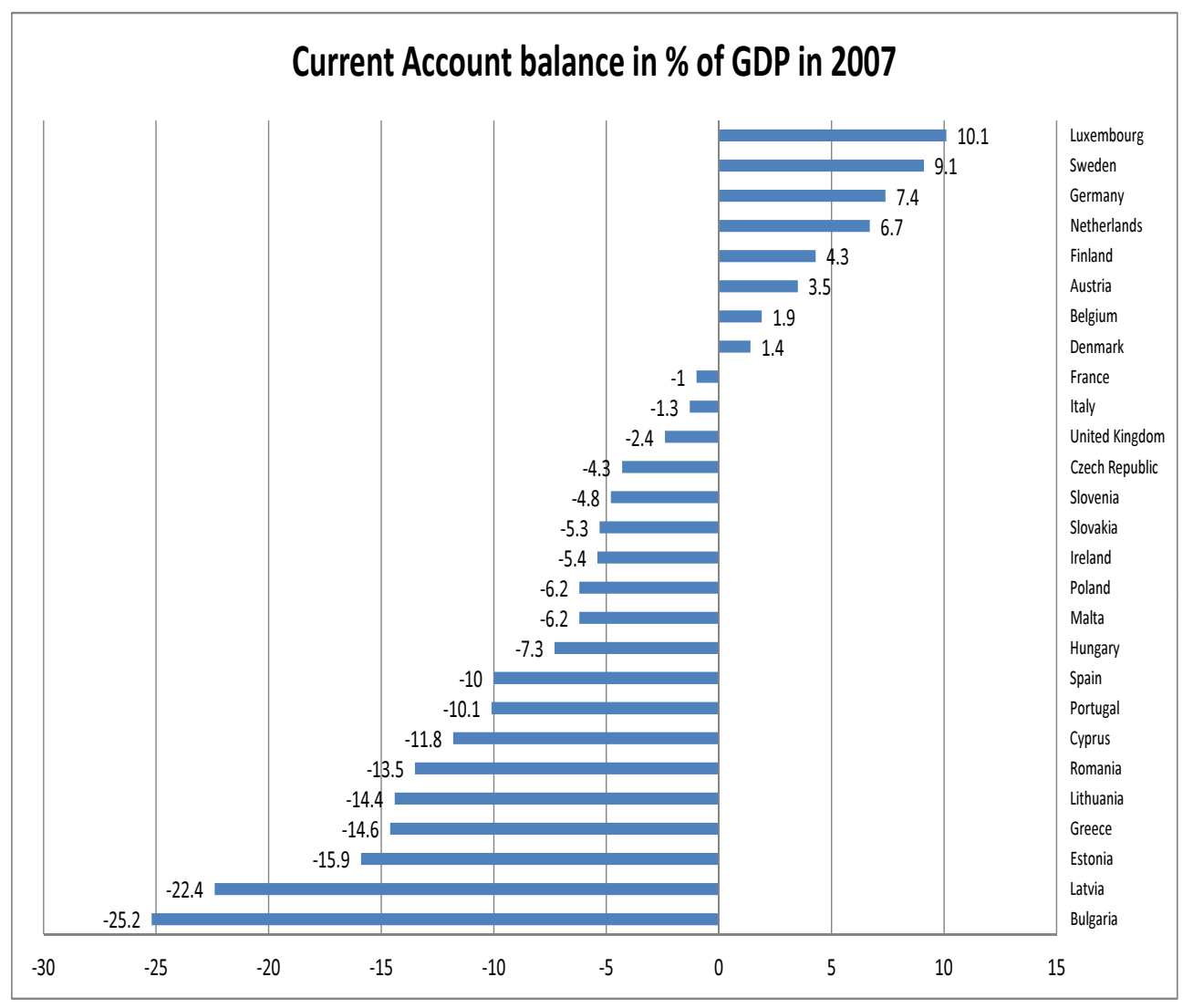

Source: Eurostat database. 
Figure 2: Current Account balance in \% of GDP, 1999-2012

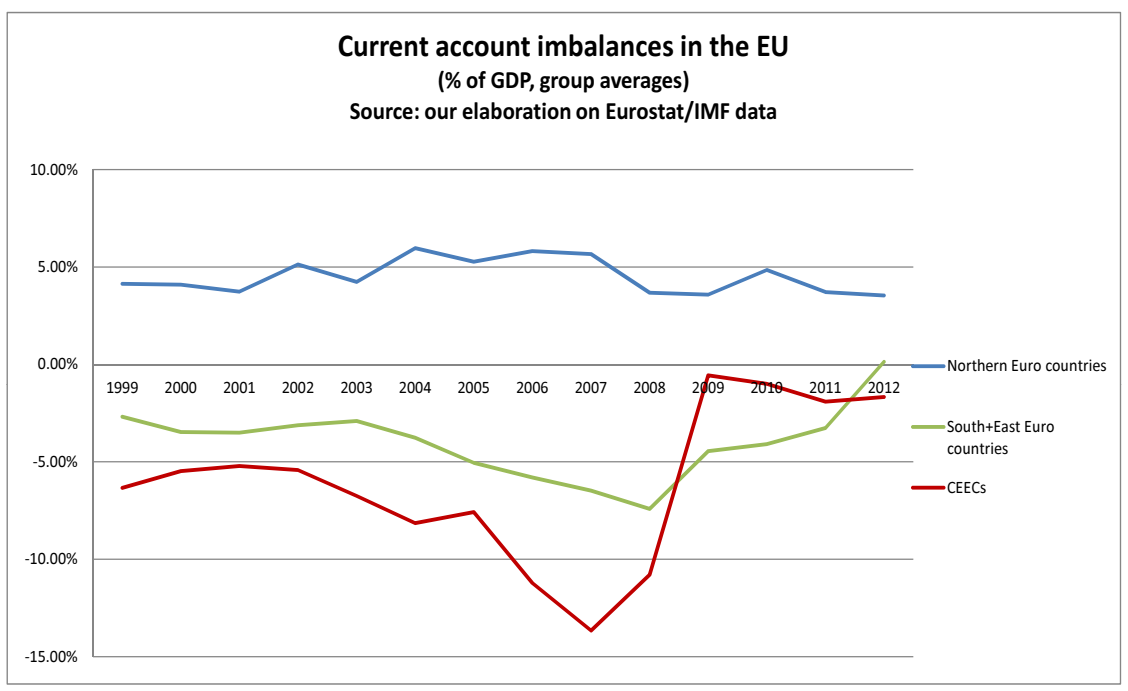

Source: our elaborations on Eurostat database.

Note: Northern Countries include Austria, Belgium, Germany, Finland, Netherlands, Luxemburg, while South and Eastern Countries include Portugal, Greece, Spain, Italy, Slovenia, Slovakia, Ireland and France. The graph displays the simple average for each group. 
Figure 3: Standard Deviation of EU members Current Account balance (\% of GDP)

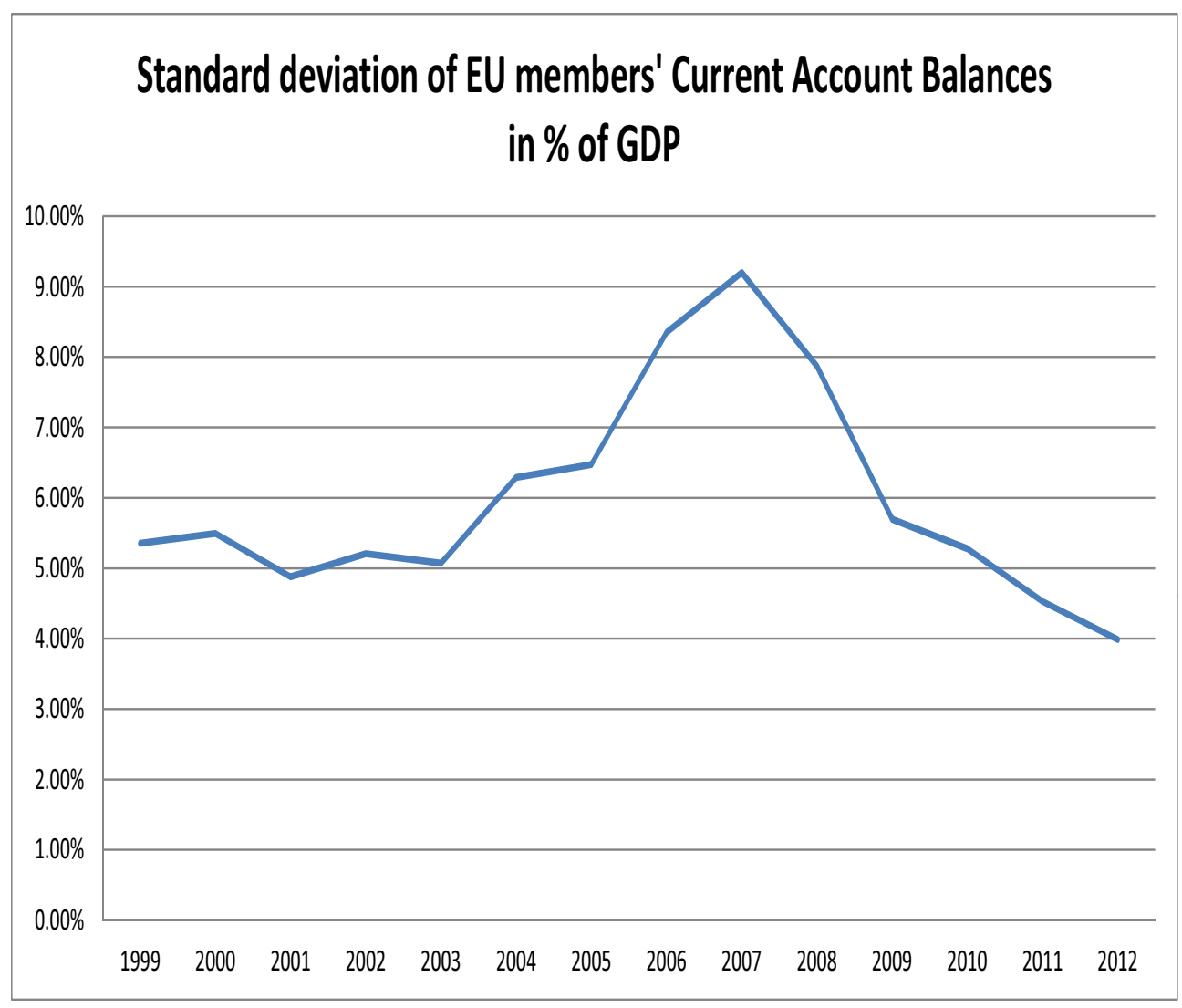

Source: Eurostat database. 


\section{Appendix}

\subsection{Partners splitting}

List of partners in WIOD data: Austria, Australia, Belgium, Bulgaria, Brazil, Canada, China, Cyprus, Czech Rep., Germany, Denmark, Estonia, Greece, Spain, Finland, France, Hungary, Indonesia, Ireland, India, Italy, Japan, Korea, Lithuania, Luxembourg, Latvia, Malta, Mexico, Netherlands, Poland, Portugal, Romania, Russia, Sweden, Slovenia, Slovakia, Turkey, Taiwan, United Kingdom, United States and Rest of the World (41, 40 plus RoW; 27 EU).

List of countries by group when the splitting is on the basis of their gdp per capita. We build the groups of countries on the basis of the median value in 1998.

- High-income countries: Austria, Belgium, Luxemburg, Netherlands, Sweden, Denmark, Spain, Finland, France, UK, Italy, Germany, Ireland, Japan, Australia, USA, Canada, Cyprus, Taiwan.

- Low-income countries: Bulgaria, Czech Rep., Hungary, Estonia, Lithuania, Latvia, Poland, Portugal, Greece, Romania, Slovakia, Slovenia, Turkey, Brazil, Mexico, India, China, Korea, Indonesia.

- Residual group: 'Rest of the World' and Russia.

Russia is excluded because of the role of oil trade in its trade relationships.

List of countries by group when the splitting is on the basis of the "normalized quality index' provided by Hallak and Shott (2010). We build the groups of countries on the basis of the median value in 1998. The classification does not change if we consider 2003.

- High-quality countries: Austria, Belgium, Netherlands, Sweden, Denmark, Finland, France, United Kingdom, Italy, Germany, Ireland, Japan, Korea, Hungary.

- Low-quality countries: Canada, Australia, Poland, Portugal, Romania, Turkey, Brazil, Mexico, India, Indonesia, China, Greece, Spain, Taiwan. 
- Residual group: RoW, Luxembourg, United States, Bulgaria, Czech Rep., Estonia, Lithuania, Latvia, Slovakia, Slovenia,Cyprus, Russia, Malta.

The residual group is larger due to the low overlapping between the countries for which Hallak and Shott (2010) provide the quality index and WIOD data.

\subsection{EU countries' classification}

- EU Eastern countries includes: Bulgaria, Czech Rep., Hungary, Poland, Romania, Slovakia, Slovenia, Estonia, Latvia, Lithuania.

- Eu13 includes: Austria, Belgium, Germany, Spain, France, Ireland, Italy, Luxembourg, Netherlands, Finland, Sweden, Denmark, United Kingdom.

\subsection{The Foreign Value Added in a country's export}

Here we describe the parts of the Inter-Country Input-Output model of Koopmans et al. (2014) that we have used to compute the foreign value-added embodied in a country's exports.

Assume a G-country world, in which each country produces goods in N differentiated sectors. Goods in each sector might be consumed directly or used as intermediate input. Each country can also export both intermediate and final goods.

All gross output produced by country $s$ must be used as either an intermediate good or a final good at home or in other countries,

$$
\mathbf{X}_{s}=\mathbf{A}_{s s} \mathbf{X}_{s}+\mathbf{A}_{s r} \mathbf{X}_{r}+\mathbf{Y}_{s s}+\mathbf{Y}_{r s} r, s=1, \ldots, G r \neq s
$$

where $\mathbf{X}_{s}$ is the $N \times 1$ gross output vector of country $s, \mathbf{Y}_{s r}$ is the $N \times$ 1 final demand vector that represent demand in country $r$ for final goods produced in $s$ and $\mathbf{A}_{s r}$ is the $N \times N$ Input-Output coefficient matrix, showing the use in $r$ of intermediate goods produced in $s$. The $G$-country production and trade system can be written as Inter-Country Input-Output model in block matrix notation

$$
\left[\begin{array}{c}
\mathbf{X}_{1} \\
\mathbf{X}_{2} \\
\vdots \\
\mathbf{X}_{G}
\end{array}\right]=\left[\begin{array}{cccc}
\mathbf{A}_{11} & \mathbf{A}_{12} & \ldots & \mathbf{A}_{1 G} \\
\mathbf{A}_{21} & \mathbf{A}_{22} & \ldots & \mathbf{A}_{2 G} \\
\vdots & \vdots & \ddots & \vdots \\
\mathbf{A}_{G 1} & \mathbf{A}_{G 2} & \ldots & \mathbf{A}_{G G}
\end{array}\right]\left[\begin{array}{c}
\mathbf{X}_{1} \\
\mathbf{X}_{2} \\
\vdots \\
\mathbf{X}_{G}
\end{array}\right]+\left[\begin{array}{c}
\mathbf{Y}_{11}+\mathbf{Y}_{12}+\ldots+\mathbf{Y}_{1 G} \\
\mathbf{Y}_{21}+\mathbf{Y}_{22}+\ldots+\mathbf{Y}_{2 G} \\
\vdots \\
\mathbf{Y}_{G 1}+\mathbf{Y}_{G 2}+\ldots+\mathbf{Y}_{G G}
\end{array}\right]
$$


and rearranging

$$
\begin{aligned}
{\left[\begin{array}{c}
\mathbf{X}_{1} \\
\mathbf{X}_{2} \\
\vdots \\
\mathbf{X}_{G}
\end{array}\right]=} & {\left[\begin{array}{cccc}
\mathbf{1}-\mathbf{A}_{11} & -\mathbf{A}_{12} & \ldots & -\mathbf{A}_{1 G} \\
-\mathbf{A}_{21} & \mathbf{1}-\mathbf{A}_{22} & \ldots & -\mathbf{A}_{2 G} \\
\vdots & \vdots & \ddots & \vdots \\
-\mathbf{A}_{G 1} & -\mathbf{A}_{G 2} & \ldots & \mathbf{1}-\mathbf{A}_{G G}
\end{array}\right]^{-1}\left[\begin{array}{c}
\sum_{r}^{G} \mathbf{Y}_{1 r} \\
\sum_{r}^{G} \mathbf{Y}_{2 r} \\
\vdots \\
\sum_{r}^{G} \mathbf{Y}_{G r}
\end{array}\right]=} \\
& {\left[\begin{array}{cccc}
\mathbf{B}_{11} & \mathbf{B}_{12} & \ldots & \mathbf{B}_{1 G} \\
\mathbf{B}_{21} & \mathbf{B}_{22} & \ldots & \mathbf{B}_{2 G} \\
\vdots & \vdots & \ddots & \vdots \\
\mathbf{B}_{G 1} & \mathbf{B}_{G 2} & \ldots & \mathbf{B}_{G G}
\end{array}\right]\left[\begin{array}{c}
\mathbf{Y}_{1} \\
\mathbf{Y}_{2} \\
\vdots \\
\mathbf{Y}_{G}
\end{array}\right] }
\end{aligned}
$$

where $\mathbf{B}_{s r}$ denotes the $N \times N$ block Leontief inverse matrix, which is the total requirement matrix that gives the amount of gross output produced in country $s$ for one-unit increase in final demand in country $r, \mathbf{Y}_{s}=\sum_{r}^{G} \mathbf{Y}_{s r}$ is the $N \times 1$ vector that gives the global use of $s$ 's final products. This system can be also expressed as:

$$
\mathbf{X}=(\mathbf{I}-\mathbf{A})^{-1} \mathbf{Y}=\mathbf{B} \mathbf{Y}
$$

where $\mathbf{X}$ and $\mathbf{Y}$ are $G N \times 1$ vectors, and $\mathbf{A}$ and $\mathbf{B}$ as $G N \times G N$ matrices.

Having defined the Leontief inverse matrix, we turn to show how domestic and foreign contents of gross exports are computed. Let $\mathbf{V}_{s}$ be the $1 \times N$ direct value-added coefficient vector. Each element of $\mathbf{V}_{s}$ gives the share of direct domestic value added in total output. This is equal to one minus the intermediate input share from all countries (including domestically produced intermediates):

$$
\mathbf{V}_{s} \equiv \mathbf{u}\left(\mathbf{I}-\sum_{r} \mathbf{A}_{r s}\right)
$$

where $\mathbf{u}$ is a $1 \times N$ unity vector. To be consistent with the Inter-Country model, we define $\mathbf{V}$ the $G \times G N$ matrix of direct domestic value added for all countries,

$$
\mathbf{V} \equiv\left[\begin{array}{cccc}
\mathbf{V}_{1} & \mathbf{0} & \mathbf{0} & \mathbf{0} \\
\mathbf{0} & \mathbf{V}_{2} & \mathbf{0} & \mathbf{0} \\
\mathbf{0} & \mathbf{0} & \ddots & \mathbf{0} \\
\mathbf{0} & \mathbf{0} & \mathbf{0} & \mathbf{V}_{G}
\end{array}\right]
$$

As in Koopman et al. (2014), combining $\mathbf{V}$ with Leontief inverse matrix B produces the $G \times G N$ value-added share (VB) matrix, $\mathbf{V B}$ is our basic measure of value-added shares by source of production: 


$$
\mathbf{V B}=\left[\begin{array}{cccc}
\mathbf{V}_{1} \mathbf{B}_{11} & \mathbf{V}_{1} \mathbf{B}_{12} & \ldots & \mathbf{V}_{1} \mathbf{B}_{1 G} \\
\mathbf{V}_{2} \mathbf{B}_{21} & \mathbf{V}_{2} \mathbf{B}_{22} & \ldots & \mathbf{V}_{2} \mathbf{B}_{2 G} \\
\vdots & \vdots & \ddots & \vdots \\
\mathbf{V}_{G} \mathbf{B}_{G 1} & \mathbf{V}_{G} \mathbf{B}_{G 2} & \ldots & \mathbf{V}_{G} \mathbf{B}_{G G}
\end{array}\right]
$$

Within $\mathbf{V B}$, each element $\mathbf{V}_{s} \mathbf{B}_{s r}$ is a $1 \times N$ vector. Vectors on the diagonal denote domestic value-added share of domestically produced $\mathrm{N}$ products. The out-diagonal vectors along columns denote instead the foreign country's value-added shares in the same domestically produced $\mathrm{N}$ products. Each of the first $\mathrm{N}$ columns in the $\mathbf{V B}$ matrix includes all value added components, domestic and foreign, needed to produce one additional unit of domestic product at home.

Because all value added must be either domestic or foreign, the sum along each column is unity.

The VB matrix contains all the information to separate domestic and imported content shares in each country's gross exports at the sectoral level.

Let $\mathbf{E}_{s r}$ be the $N \times 1$ vector of gross exports from $s$ to $r$. For consistency with the Inter-Country Input-Output model we also define

$$
\begin{gathered}
E_{s *}=\sum_{r \neq s}^{G} \mathbf{E}_{s r}=\sum_{r \neq s}^{G}\left(\mathbf{A}_{s r} \mathbf{X}_{r}+\mathbf{Y}_{s r}\right) r, s=1 \ldots G \\
\mathbf{E}=\left[\begin{array}{cccc}
\mathbf{u} E_{1 *} & \mathbf{0} & \ldots & \mathbf{0} \\
\mathbf{0} & \mathbf{u} E_{2 *} & \ldots & \mathbf{0} \\
\vdots & \vdots & \ddots & \vdots \\
\mathbf{0} & \mathbf{0} & \ldots & \mathbf{u} E_{G *}
\end{array}\right]=\left[\begin{array}{cccc}
\mathbf{E}_{1 *} & \mathbf{0} & \ldots & \mathbf{0} \\
\mathbf{0} & \mathbf{E}_{2 *} & \ldots & \mathbf{0} \\
\vdots & \vdots & \ddots & \vdots \\
\mathbf{0} & \mathbf{0} & \ldots & \mathbf{E}_{G *}
\end{array}\right]
\end{gathered}
$$

where $\mathbf{E}$ is a $G N \times G$ export matrix and each element $\mathbf{E}_{s *}=\mathbf{u} E_{s *}$ is a $N \times 1$ vector given by the product of the unity $N \times 1$ vector $\mathbf{u}$ and the scalar $E_{s *}$.

The combination of value added share matrix $\mathbf{V B}$ and the export matrix $\mathbf{E}$ produces a $G \times G$ matrix $(\mathbf{V B E})$ that represents the aggregate measures of value-added by origin in countries gross exports

$$
\mathbf{V B E}=\left[\begin{array}{cccc}
\mathbf{V}_{1} \mathbf{B}_{11} \mathbf{E}_{1 *} & \mathbf{V}_{1} \mathbf{B}_{12} \mathbf{E}_{2 *} & \ldots & \mathbf{V}_{1} \mathbf{B}_{1 G} \mathbf{E}_{G *} \\
\mathbf{V}_{2} \mathbf{B}_{21} \mathbf{E}_{1 *} & \mathbf{V}_{2} \mathbf{B}_{22} \mathbf{E}_{2 *} & \ldots & \mathbf{V}_{2} \mathbf{B}_{2 G} \mathbf{E}_{G *} \\
\vdots & \vdots & \ddots & \vdots \\
\mathbf{V}_{G} \mathbf{B}_{G 1} \mathbf{E}_{1 *} & \mathbf{V}_{G} \mathbf{B}_{G 2} \mathbf{E}_{2 *} & \ldots & \mathbf{V}_{G} \mathbf{B}_{G G} \mathbf{E}_{G *}
\end{array}\right]
$$


Diagonal elements of VBE define the domestic value-added in each countrys gross exports. Off-diagonal elements along each column give the foreign value-added embodied in each countrys exports by origin. Therefore, gross exports of country $s$ can be decomposed into two components: domestic value-added content of gross exports $\left(D V_{s}\right)$ and foreign value-added content of gross exports $\left(F V_{s}\right)$ as follows

$$
\begin{gathered}
\mathbf{D V}=\left[\begin{array}{c}
D V_{1} \\
D V_{2} \\
\vdots \\
D V_{G}
\end{array}\right]=\left[\begin{array}{c}
\mathbf{V}_{1} \mathbf{B}_{11} \mathbf{E}_{1 *} \\
\mathbf{V}_{2} \mathbf{B}_{22} \mathbf{E}_{2 *} \\
\vdots \\
\mathbf{V}_{G} \mathbf{B}_{G G} \mathbf{E}_{G *}
\end{array}\right] \\
\mathbf{F V}=\left[\begin{array}{c}
F V_{1} \\
F V_{2} \\
\vdots \\
F V_{G}
\end{array}\right]=\left[\begin{array}{c}
\sum_{r \neq 1} \mathbf{V}_{r} \mathbf{B}_{r 1} \mathbf{E}_{1 *} \\
\sum_{r \neq 2} \mathbf{V}_{r} \mathbf{B}_{r 2} \mathbf{E}_{2 *} \\
\vdots \\
\sum_{r \neq G} \mathbf{V}_{r} \mathbf{B}_{r G} \mathbf{E}_{G *}
\end{array}\right]
\end{gathered}
$$

FV and DV are both $G \times 1$ vectors. Elements of $\mathbf{F V}$ are the result of the sum of out-diagonal elements along each column of VBE.

It holds that for the generic country $s$

$$
E_{s *}=\mathbf{V}_{s} \mathbf{B}_{s s} \mathbf{E}_{s *}+\sum_{r \neq s} \mathbf{V}_{r} \mathbf{B}_{r s} \mathbf{E}_{s *}
$$

Therefore we can easily derive the aggregate measures of domestic and foreign shares of value-added incorporated in country $s$ gross exports as

$$
\begin{aligned}
& D V A_{s}=D V_{s} / E_{s *} \\
& F V A_{s}=F V_{s} / E_{s *}
\end{aligned}
$$

Note that measures indicated here as DV are instead denoted in Koopmans et al. (2014) as DC standing for domestic content of gross export; measures indicated here as FV are instead labeled in Koopmans et al. (2014) as VS standing for the foreign content of gross exports. VS indeed corresponds to the index proposed by Hummels et al. (2001) for measuring vertical specialization. 